\title{
CORRIGENDUM
}

\section{Effects of telmisartan on the cerebral circulation of hypertensive patients with chronic-stage stroke}

Ichiro Deguchi, Daisuke Furuya, Takuya Fukuoka and Norio Tanahashi

Hypertension Research (2012) 35, 1204; doi:10.1038/hr.2012.139

Correction to: Hypertension Research (2012) 35, 1171-1175;

doi:10.1038/hr.2012.105; published online 5 July 2012

Since the publication of this article, the errors in Figure 3 and in Table 1 have been noticed. The errors have now been rectified, and the correct article appears in this issue. The html and online pdf versions have also been rectified. 